\title{
The interaction coexistence between screen culture and internet culture on "Internet +" Era
}

\author{
Yuzhen Cao ${ }^{\mathrm{a}}$, Jie Cai \\ Nanchang Institute of Technology, Nanchang 330044, China \\ a103006664@qq.com
}

Keywords: Internet, Online booking, capricious, Internet marketing

\begin{abstract}
The internet create an information globalization era by its transcendental charm of information spreading on cross-region, cross-time and vivid. The dependence severity on the internet by all walks of life has reached an unprecedented height. What kind of sparkling will generate by the crash between screen and internet is the subject that should be observe, research and discuss by the contemporary media people. "Internet + screen" combine the traditional screen culture and the internet, and further force the several emerging cultural patterns such as the online booking, internet marketing, and so on. This is the challenge to the traditional media and the development opportunity of the new media at the same time. This report will focus on the discussion of "Internet +" Era by extensive view, which will think about the new social culture phenomenon that is forced by the interaction between the screen culture and internet culture.
\end{abstract}

Culture including spiritual culture and material culture. From the narrow aspect, it refers to the social ideology. Its formation with the unique times characteristics which based on the internet information technology. Screen culture broadly refers to the cultural creation activities via media. Screen culture with the network culture change the behavior pattern and ideology of person. This combination is the major social culture phenomenon, the "Internet +" era arrived in the round.

\section{Networked approach of buy ticket}

The data from IiMedia Research demonstrated that the box office revenue of the Chinese mainland reached 10.31 billion yuan. Below-the-line revenue accounted for only $30.6 \%$ of the total box office revenue, the remaining $69.4 \%$ is online income. Online ticketing has become the main approach of the cinema ticket booking. The following is the reasons of this phenomenon:

\subsection{Younger Audience group}

The age level of the audience group who like to watching movie at the cinema concentrated in the 15 years old to 35 years old age group, which is account for $75 \%$ of the total viewing group. According to the research report of the $39^{\text {th }}$ China Internet development Survey released on January 22th 2017, until to December 2016, the number of China internet users has equivalent to the total population of Europe, which account for $73.7 \%$ of the total population and major on the 10 years old to 39 years old age group. The age bracket of this group is the generation after $80 \mathrm{~s}$, 90s, and 00s. These three groups are familiar with the use of network, and without any obstacles of the online booking operation.

\subsection{Multi-platform Mobile APP}

The meaning of the Appstore model is that the third-party software providers provide a convenient and efficient sale platform to public. At present, the mainly online booking APP platform has: Taopiaopiao, Maoyan Movie, and so on. Not only about the convenient and fast online booking, these online movie ticket platform can also releasing the latest film dynamic, checking the upcoming film schedule, and selecting the seat. The APP provide the one-stop service, which improve the public rely on the online booking platform. 


\subsection{Cinema distribution urbanization}

Cinema is the terminal of the film industry chain, the first part of the box office revenue, and one of the main dependencies of the film industry chain to achieve profitability and recovery costs. The mainstream of cinema in China is city cinema, the cinema at first-line city is more concentrated. In despite of the cinema construction at the second and third tier cities is development well in recent years, the cinema distribution at the relatively remote township is almost zero. Based on the China urban and rural network structure distribution, the urban netizens accounted for nearly 3/4 of the national netizens, which indicating that the urban population is the main force of film consumption. So than, the urbanization of the cinema distribution is inevitable. After all, the film industry is a commercial industry, the investors is required about the return.

\section{Capricious approach of watching film}

The traditional way of watching movie is the audience enter into the public theater to enjoy the movie, they do not have much choice on watching schedule, place, and environment and so on. At present, there would use a word to summarize the watching form which is "capricious".

\subsection{Capricious watching time and space}

The author as a witness of the development of film industry, watching movie at open-air cinema, cinema, until at the family cinema. Internet access to China and universal so far, the internet era coming, and the mobile Wi-Fi achieved full coverage. Internet users as long as to carry a mobile phone, IPA or laptop computers can online viewing movie anytime, anywhere. Or they could downloaded the videos, stored it on the portable device, then people could see these videos at any place as they want, which can been said as "capricious".

\subsection{Capricious content selection}

At Traditional cinema, a viewing hall will arranged a movie once which cannot meet the needs of modern film audience. But the modern cinema equipped with a number of viewing hall. It can synchronized projection several movies according to the demand, which can satisfies the selectivity of the viewers. On the other hand, the audience could choose movie online with a wider range. The online video sites, such as Youku, iQIYI, including movie, TV series, documentary, and so on. At the same time, the design of each site is also very user-friendly, all resources are in accordance with the country region, release year, the type of video classification, to facilitate the choice of Internet users. Therefore, the Internet users could choose video with their own preferences and willingness, which is performance of capricious content selection. With the continuous development of science and technology, home theater, 3D theme theater, car theater system, and these film system is the solid backing to the capricious viewing.

\section{Promotion channel diversification}

A good screen work need to achieve the purpose of achieving high box office through self-promotion. Rely on the network, the screen channel promotion reflects its diversity features.

\subsection{Micro-blogging Marketing}

As the Internet social media marketing, the micro-blogging marketing focus on the use of microblogging manufacturing speculation or be the opinion leaders lead. For example, Han Han is a popular microblog user at Sina Weibo, during the release period of "The Continent", his main strategy is use microblogging to gather popularity, and conducting the virus spread for the film to create a good publicity effect. Han Han has more than 40 million microblogging fans, his fans have become network promoter for his film.

\subsection{Theme Song Marketing}

The synonym theme song of Youth New Year film "Back in time" is singing by Faye Wong. 
After MV release on internet, the audition on QQ Music break 15 million in 5 days, it became one of the 2014 gold songs. Theme song marketing has become an indispensable part for current film manufacturing industry. A good theme song is correspond to the movie story and infectious, which could be emotionally touched the audience's heart, resulting in the heart of the resonance. This will directly transfer to the audience expectations to the film story, and ultimately promote the high box office. Thus, the pre-heating before film publicity, theme song marketing is one of the effective approaches that producers could choose which is also cost effective.

\subsection{Video Marketing}

TV series "The journey of Flower" which is adaptation by the synonym network novel, present the aesthetic videos, such as the promo "when Huo Jianhua met Bai Zihua". The name of actors has become the hot keywords on the internet immediately. The English version trailer has added unlimited possibilities for the overseas market. In order to meet the interactive needs of fans, the film side directly provides the high-definition download. The fans produce different MV to the public platform which result in the boom of interactive marketing model, achieve the real "zero distance contact" with fans. "The quality of the film determines how far the film can fly, the marketing determines how high it can fly." Data show that, China's film audience and Internet audience has a high degree of coincidence in crowd structure. Thus, these traditional film marketing, such as the movie trailer, combined with the network to promote also could achieve good promotion effect. Therefore, even as a supporting role, the screen producers that do not miss any approaches of the marketing promotion.

\section{Interactivity of the comment form}

The screen works only has the relationship with audience after they seen it. The audience could comment on the works after they seen it. At the internet era, the interactive problems solved.

\subsection{Message interaction}

Screen culture can be described as popular culture, but the public is just seen watching movies as simple entertainment. The Internet has changed this phenomenon, so that makes the screen culture has become the popular culture in real sense. All of the audience can participate in the comment to the screen works through the network, the message interaction is the most basic way of network interaction. For example, A post the film critics to the movie he already seen through the film critics website, such as Dianping, and so on. B respond it on internet.

\subsection{Real-time interaction.}

At present, when audience watching the video on the online site, there will has a "弹” word below the player screen. This is the Barrage. Barrage video system can give the audience a "real-time interaction" illusion. Although there has the post time is different among the different barrage, it will only appear in the video at a specific point in time. So that the barrages sent at the same time basically have the same theme. There will be an illusion to the audience that they are commenting with other audiences when participating in barrage. In fact, the barrage has the shortcoming that it will blocked the video content, and it will reduce the audience attention on the video. But no matter what, it is also a new approach of interactive commentary.

\section{Conclusion}

At the "Internet + " era, the Coexistence of screen culture and network culture promote the development of screen industry, which generate the online booking, internet marketing, online film critics and other new culture form. Internet as the emerging media, the information dissemination speed is far quicker than the other traditional media, which is well-deserved that to attribute network culture to public culture. "Internet + screen" will combine the network with the traditional public culture, which promote the mutual benefit and common development. "Internet +" era is the 
big stage that promoted by the traditional industry and network.

\section{References}

[1] YI Hong. Introduction to Contemporary Film Art [J].Higher Education Press.2007

[2] SHAO Peiren. Communication Studies [G]. Higher Education Press.2006

[3] YU Mingyang, CHEN Xianhong[F].Fudan University Press.2007

[4] Bosi Data Research Center, 2016-2022 China Cinema marketing research [G]. 2016

[5] CNNIC, China Internet development statistic Report [G]. CNNIC PRESS, 2016 